\title{
STUDIES ON BILIRUBIN SULFATE AND OTHER NONGLUCURONIDE CONJUGATES OF BILIRUBIN $* \dagger$
}

\author{
By KURT J. ISSELBACHER AND ELIZABETH A. McCARTHY \\ (From the Department of Medicine, Harvard Medical School, and the Medical Services, \\ Massachusetts General Hospital, Boston, Mass.)
}

(Submitted for publication November 11, 1958; accepted November 25, 1958)

As a result of the important observations of Billing, Cole and Lathe (2, 3), Schmid (4) and Talafant (5), it is now clear that "direct-reacting" bilirubin is a polar and water soluble conjugate of bilirubin. These investigators have provided evidence that this conjugate is a diglucuronide formed primarily in the liver, and recently it has been shown that the glucuronic acid is attached at the two carboxyl groups of the bilirubin molecule (6). Since the hepatic conjugation of alcoholic and phenolic compounds, such as corticosteroids and estrogens, involves the formation of sulfate as well as glucuronide derivatives, it seemed reasonable that an ethereal sulfate derivative of bilirubin at its hydroxyl groups might also occur. Such a derivative would be water soluble, but in contrast to the alkali labile glucuronide ester, the ethereal sulfate would be alkali stable. Previous observations by Billing and associates (3) that 5 to 40 per cent of human bile pigments were alkali stable gave additional support for this hypothesis.

The present study provides evidence for the physiologic occurrence of bilirubin sulfate as well as other, as yet unidentified, nonglucuronide conjugates of bilirubin in the bile of animals and man.

\section{MATERIALS AND METHODS}

Experiments with radioactive sulfate. Polyethylene catheters were inserted into the bile ducts of rats, after which the animals were injected subcutaneously and intraperitoneally with 1 to $2 \mu \mathrm{c}$. of inorganic $\mathrm{S}^{35} \mathrm{O}_{4}$ in normal saline. Bile was collected while the animals were in restraining cages. In cats, the bile was collected from the gall bladder and in man from $\mathrm{T}$-tube drainages after the injection of labeled sulfate.

For diazotization bile was first brought to $\mathrm{pH} 4$ to 5 . Then diazotization was carried out in the usual manner (3) with sulfanilic acid, $p$-aminobenzoate or aniline.

\footnotetext{
1 This investigation was supported in part by Research Grant A-1392 from the National Institutes of Health.

$\dagger$ A preliminary communication of this work has appeared previously (1).
}

Purification procedures and chromatography. The diazotized pigments were washed with heptane-butanol and chloroform (7) and then extracted into $n$-butanol. The solvent was brought to dryness by vacuum distillation in a flash evaporator and redissolved in water. For further purification, the pigments were added to a suspension of $\mathrm{Zn}(\mathrm{OH})_{2}$ gel at $\mathrm{pH} 6$. The gel was washed as previously described (1) and then dissolved in $0.5 \mathrm{~N} \mathrm{HCl}$. The pigments were again extracted into $n$-butanol, the solvent removed by vacuum distillation and prepared for chromatography by dissolving in $1 \mathrm{~N}$ acetic acid.

Ascending paper chromatography was carried out on Whatman No. 1 paper using three solvent systems : $n$-propionic acid-methyl ethyl ketone-water (25:75:30) (4); $n$-butanol-glacial acetic acid (4:1); pyridine-ethyl acetate-water $(1: 2: 1)$. Pigments were eluted from paper with $0.05 \mathrm{~N} \mathrm{HCl}$ and their absorbency at $560 \mathrm{~m} \mu$ determined in a Beckman DU spectrophotometer. The molecular extinction coefficient for azobilirubin under these conditions was 11.5.

Enzymatic hydrolysis with bacterial $\beta$-glucuronidase (obtained from Sigma Chemical Company, St. Louis, Mo.) was carried out at $37^{\circ} \mathrm{C}$. for 24 hours at $\mathrm{pH} 6.2$ using acetate buffer at a final concentration of $0.1 \mathrm{M}$. Fifty $\mathrm{mg}$. of enzyme was added initially and again 12 to 16 hours later. The sulfatase preparation was a commercial arylsulfatase known as Mylase-P ${ }^{\circledR}$ (Wallerstein Laboratories, New York).

Reactions with hydroxylamine were carried out as described by Schachter (6). Methylation was carried out by exposing the pigments on paper to an atmosphere of diazomethane. Diazomethane was prepared from $\mathrm{N}$-methyl-N-nitroso- $p$-toluene sulfonamide (8). The latter was obtained as Diazald ${ }^{\circledR}$ from the Aldrich Chemical Company, Milwaukee, Wis.

Sulfate determination. The bile azopigments were washed and purified as above and chromatographed in the pyridine system. After elution, the amount of azopigment was determined spectrophotometrically. Two $1 \mathrm{ml}$. aliquots of the pigments were transferred to test tubes to which was added $1 \mathrm{ml}$. of 20 per cent trichloracetic acid. One tube was heated at $100^{\circ} \mathrm{C}$. for 90 minutes, while the other was kept at $0^{\circ} \mathrm{C}$. as a control. Then $5 \mathrm{ml}$. of 1 per cent recrystallized benzidine was added to each tube and the sulfate measured by the method of Dodgson and Spencer (9). The sulfate liberated by hydrolysis was determined from a standard curve which had been prepared using potassium sulfate. Hydrocholic acid was used 


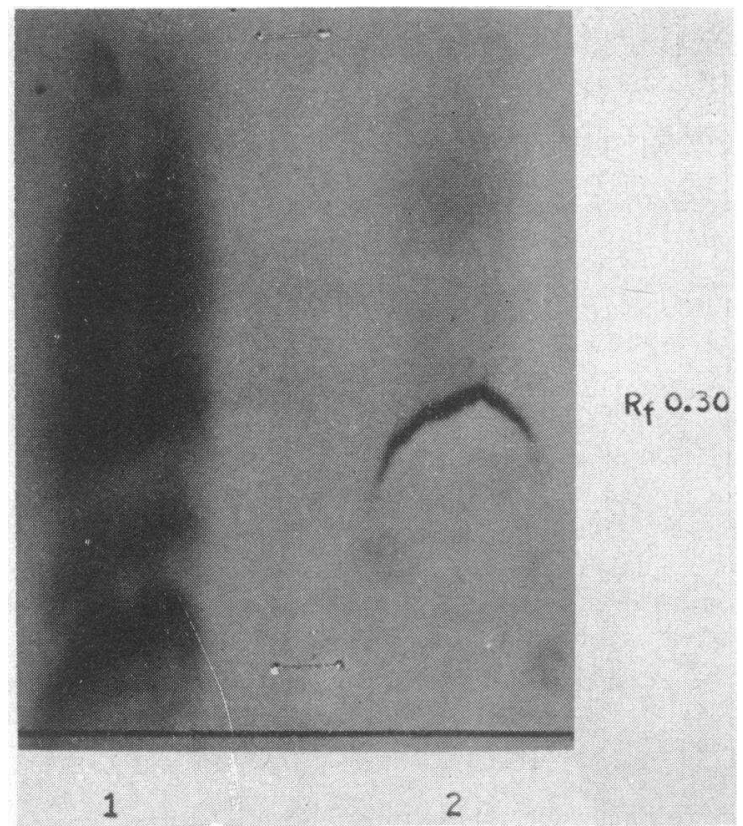

Fig. 1. Chromatography of Rat Bile After Injection of Radioactive Sulfate

Chromatographic system was the propionic acid system of Schmid (4). Column 1 indicates the results of the bile after diazotization and extraction into butanol. Column 2 is the same bile but after purification with $\mathrm{Zn}(\mathrm{OH})_{2}$ gel.

initially in the hydrolysis but was abandoned because it interfered with the sulfate method and gave erratic results.

Preparation of synthetic "bilirubin sulfate." 1. Reaction with Liebermann-Burchard reagent. Bilirubin was dissolved in chloroform and then reacted with the Liebermann-Burchard reagent (10). Usually inorganic $\mathrm{S}^{35} \mathrm{O}_{4}$ was also added. After one minute, the reaction mixture was added to water and the lower chloroform layer removed. The yellow-green aqueous solution was then washed three times with chloroform and diazotized with sulfanilic acid. The azopigments were extracted into $n$-butanol and the latter removed by vacuum distillation as above. The dried pigments were then dissolved in water or $1 \mathrm{~N}$ acetic acid.

2. Chlorosulfonic acid method. To a solution of 10 mg. of bilirubin in $10 \mathrm{ml}$. of dry pyridine at $0^{\circ} \mathrm{C}$. was added dropwise $1 \mathrm{ml}$. of redistilled chlorosulfonic acid (11). Constant stirring with a magnetic stirrer was maintained during the addition of the acid and continued for 30 minutes thereafter. After standing overnight at $0^{\circ} \mathrm{C}$., ice was added to dilute the chlorosulfonic acid. The $\mathrm{pH}$ was adjusted to $\mathrm{pH} 4$ to 5 and diazotized sulfanilic acid added. Extraction into butanol was carried out as above.

Other procedures. Stability of pigments to alkali was carried out by neutralizing the solutions of azopigment and then adding $\mathrm{NaOH}$ to give a final concentration of $0.1 \mathrm{~N}$. After standing at room temperature for $10 \mathrm{~min}$ - utes, the solution was acidified and extracted into $n$-butanol.

Glucuronic acid was measured by the naphthoresorcinol method as described by Fishman and Green (12).

\section{RESULTS}

\section{Demonstration of $S^{35}$-labeled azopigments in bile}

In the initial studies carried out in rats with biliary fistulas, the injection of $\mathrm{S}^{35}$-labeled sulfate resulted in the excretion of numerous radioactive products in bile as shown by paper chromatography and autoradiography (Figure 1, Chromatogram 1). After purification by extraction procedures, followed by adsorption and elution from $\mathrm{Zn}(\mathrm{OH})_{2}$ gel, one major radioactive metabolite remained which migrated with the conjugated azopigment of bile (Figure 1, Chromatogram 2). When this band was eluted and rechromatographed in any of three solvent systems, the radioactivity still remained with the azopigment band (Figure 2). Acid hydrolysis of this eluted

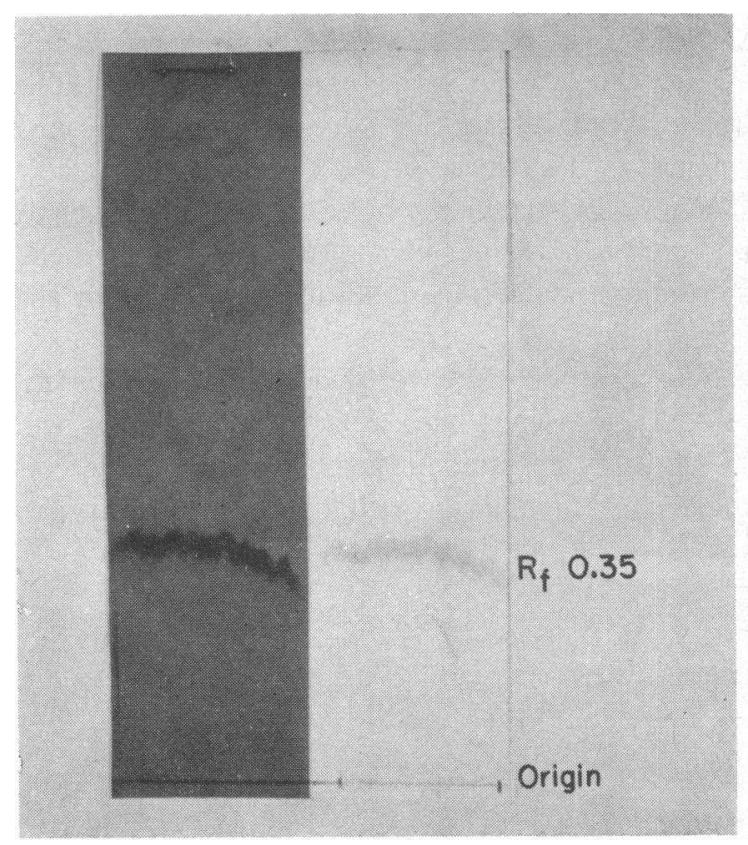

Fig. 2. Rechromatography and Autoradiography of Rat Bile Azopigment After Injection of Radioactive Sulfate

This conjugated azopigment was eluted from the propionic acid system and rechromatographed in the pyridine system. The azopigment is pictured on the right and the corresponding autoradiograph is shown at the left. It will be noted that the radioactivity directly coincides with pigment zone. 
TABLE I

Analysis of human T-tube bile azopigments

\begin{tabular}{cccr}
\hline $\begin{array}{c}\text { Patient } \\
\text { no. }\end{array}$ & $\begin{array}{c}\text { Per cent } \\
\beta \text {-glucuronidase } \\
\text { resistant* }\end{array}$ & $\begin{array}{c}\text { Per cent } \\
\text { containing } \\
\text { sulfate† }\end{array}$ & $\begin{array}{c}\text { Per cent } \\
\text { alkali } \\
\text { stable† }\end{array}$ \\
\hline B-1 & 16.8 & 7.0 & 6.8 \\
B-2 & 16.7 & 9.4 & 11.7 \\
B-3 & 19.9 & 13.6 & 14.9 \\
B-4 & 20.0 & 11.1 & 12.2 \\
B-6 & 16.7 & 7.1 & 6.8 \\
B-8 & 28.8 & 17.5 & 16.4 \\
B-10 & 30.4 & 15.0 & 20.2 \\
B-11 & 28.0 & 8.0 & 9.4 \\
B-14 & $34.6(28.6)$ & 22.6 & 24.6 \\
B-15 & $27.4(26.0)$ & 19.6 & 21.9 \\
B-16 & $20.9(20.0)$ & 20.1 & 20.0 \\
& 23.7 & 13.7 & 15.0 \\
Mean & \pm 6.4 & \pm 5.6 & \pm 6.2 \\
S. D. & & & \\
\hline
\end{tabular}

* Azopigments were treated as described in text and exposed to $\beta$-glucuronidase for 24 hours at $37^{\circ} \mathrm{C}$. Parentheses indicate values of $\beta$-glucuronidase resistant fraction, where azopigments were first chromatographed and eluted prior to enzyme treatment. These values have not been included in the calculation of the mean or standard deviation.

$\dagger$ Analyses for acid hydrolyzable sulfate were performed on $\beta$-glucuronidase resistant fraction and expressed as per cent of total pigment (micromoles of inorganic sulfate liberated per micromoles of total azopigment).

$\ddagger$ Expressed as per cent of conjugated azopigment remaining after exposure to a final concentration of $0.1 \mathrm{~N}$ $\mathrm{NaOH}$ for 10 minutes at $25^{\circ} \mathrm{C}$.

labeled pigment in $1 \mathrm{~N} \mathrm{HCl}$ at $100^{\circ}$ for 90 minutes resulted in the liberation of radioactive inorganic sulfate, as demonstrated by chromatography. Taurine was not detected as a product of this hydrolysis at any time. Similar results have been obtained in the bile of the cat as well as in human T-tube bile after the injection of $\mathrm{S}^{35} \mathrm{O}_{4}$. Experiments were also carried out in rats with surgically ligated bile ducts. When radioactive sulfate was injected into these jaundiced animals, labeled conjugated azobilirubin pigments were demonstrable in the urine and serum.

These observations supported the physiologic occurrence of a sulfate containing bilirubin pigment migrating on paper chromatograms in the area of the major conjugated azobilirubin pigments. This indicated that the polar pigment zone was not chemically pure but contained at least two conjugates of azobilirubin, glucuronide and sulfate. The experiments with radioactive sulfate, however, permitted no index as to the quantitative formation or excretion of sulfate versus glucuronide conjugates and therefore the chemical analyses described below and represented in Table I were carried out.
The labeled azopigment eluted from paper chromatograms was treated with a commercial arysulfatase, Mylase- $\mathrm{P}^{\circledR}$, but radioactive sulfate was not liberated by this crude enzyme. However this commercial preparation also did not attack any of the synthetic sulfate derivatives of bilirubin described below. Since mammalian and bacterial sulfatases, in contrast to $\beta$-glucuronidase, are quite specific and will attack some sulfate conjugates and not others (13), these results were not unexpected.

\section{Additional evidence for noncarboxyl-linked con- jugates of bilirubin}

1. Resistance to $\beta$-glucuronidase hydrolysis. The demonstration by Schachter (6) that bilirubin glucuronide reacts with hydroxylamine to form a hydroxamate derivative has provided evidence that the glucuronide molecule is linked at the carboxyl group. This is also in keeping with the relative alkali lability of conjugated bilirubin, since carboxyl conjugates are readily split by alkali. However, Billing, Cole and Lathe (3) noted that the incubation of bile in $0.06 \mathrm{~N} \mathrm{NaOH}$ resulted in the persistence of a definite yet variable amount of alkali stable pigment (5 to 40 per cent). This

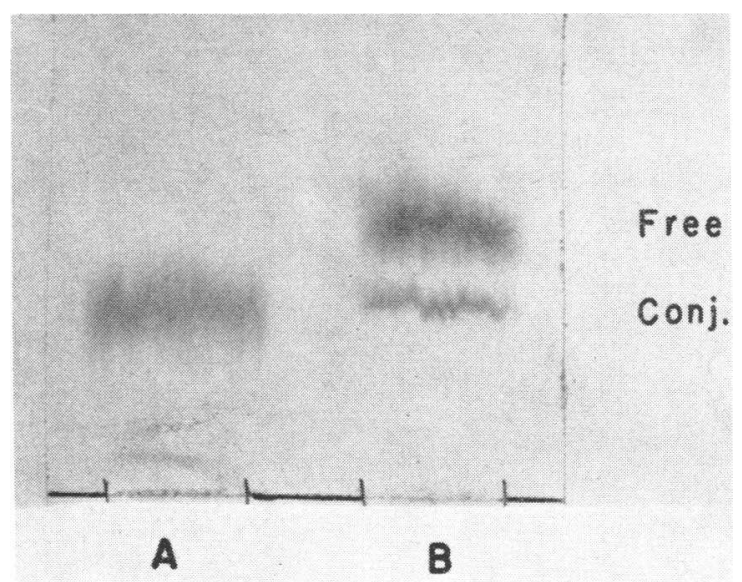

Fig. 3. Results of $\beta$-Glucuronidase Treatment of Human Bile Azopigments

Human T-tube bile was diazotized, extracted into butanol and washed as described in text. The azopigments were then exposed to bacterial $\beta$-glucuronidase for 24 hours at $37^{\circ}$ and then chromatographed in the pyridine system. $A$ represents the control which was not incubated. $B$ represents the azopigments after $\beta$-glucuronidase treatment. It will be seen that some conjugated azopigment remains after enzymatic hydrolysis. 


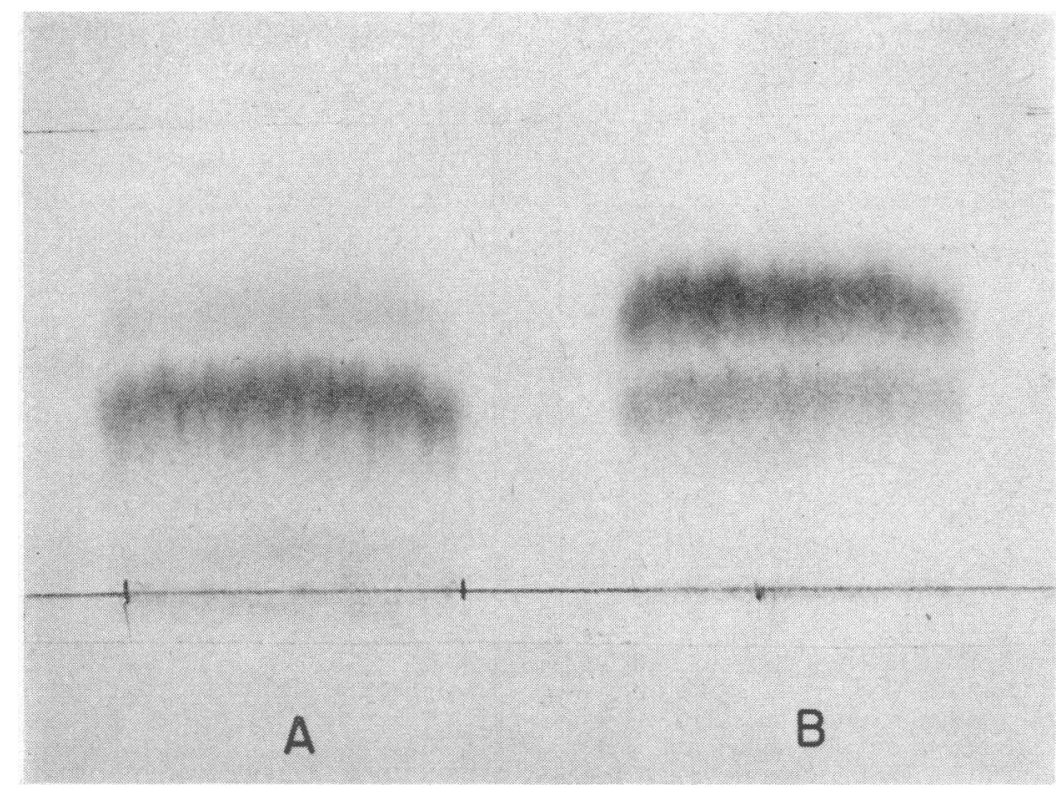

Fig. 4. Effect of Alkali on Human Bile Azopigments

Bile was diazotized and exposed to a final concentration of $0.1 \mathrm{~N} \mathrm{NaOH}$ for 10 minutes at $25^{\circ} \mathrm{C}$. It was then acidified, washed, extracted into butanol and chromatographed. $A$ represents nonalkali treated control. $B$ shows residual pigment in conjugated zone after alkali treatment.

suggested that conjugates other than acyl-glucuronides of bilirubin probably existed.

We have repeatedly observed that the incubation of human bile azopigments with bacterial $\beta$ glucuronidase results in the persistence of a conjugated azobilirubin pigment on paper chromatography (Figure 3 ). Since bile itself is inhibitory to $\beta$-glucuronidase, the pigments were purified prior to incubation, either by treatment with organic solvents (as described under Methods) or by preliminary paper chromatography and elution. Absence of inhibitors to $\beta$-glucuronidase was shown by demonstrating that added phenolphthalein glucuronide was completely hydrolyzed under these conditions. It was realized that the presence of a $\beta$-glucuronidase resistant, polar azopigment did not exclude the possibility of an $\mathrm{N}$-glucuronide, a linkage which is not susceptible to hydrolysis by the enzyme. For this reason numerous quantitative chemical analyses were carried out on the polar pigment remaining after incubation with $\beta$-glucuronidase. Repeated determinations on different samples failed to detect any glucuronic acid in this residual polar pigment. Table I indicates the results of $\beta$-glucuronidase treatment of the azopigments of human
T-tube bile obtained from patients with cholelithiasis or common duct stones but without evident liver disease. In 11 samples this $\beta$-glucuronidase resistant fraction ranged from 16.7 to 34.6 per cent with a mean of $23.7 \pm 6.4$ per cent.

2. Alkali stability. We have also carried out studies on the alkali stability of human bile pigments. In view of the fact that an alkaline $\mathrm{pH}$ promotes the oxidation of bilirubin and its conjugates to biliverdin derivatives (which do not react with the diazo reagent), the bile pigments were first diazotized and then tested for their alkali stability. Exposure of the azopigments to a final concentration of $0.1 \mathrm{~N} \mathrm{NaOH}$ for $10 \mathrm{~min}$ utes at room temperature resulted in the persistence of a pigment in the polar zone on chromatography (Figure 4). The amounts of this alkali stable pigment have varied from 6.8 to 24.6 per cent with a mean of $15.0 \pm 6.2$ per cent in 11 different specimens (Table I). As was to be expected, this pigment appeared to possess a free carboxyl group. This was supported by the fact that it did not react with hydroxylamine, but did yield a methyl derivative after treatment with diazomethane. The latter was identified by ascending chromatography in the pyridine system. 
Higher concentrations of alkali or longer incubations at room temperature did not appreciably affect the per cent of alkali stable pigment remaining. It will be noted in Table I that our values are lower than those of Billing, Cole and Lathe (3). These authors used a final concentration of $0.06 \mathrm{~N} \mathrm{NaOH}$ compared to $0.1 \mathrm{~N} \mathrm{NaOH}$ in the experiments reported here.

3. Hydrolyzable sulfate content of human bile azopigments. The conjugated azopigments isolated by paper chromatography after treatment with either $\beta$-glucuronidase or alkali were subjected to acid hydrolysis as described under Methods and the micromoles of inorganic sulfate liberated per micromole of azopigment determined. The results on 11 samples of human T-tube bile (expressed in terms of the total bile azopigments) indicate that 7.0 to 22.6 per cent of the azopigments contained hydrolyzable inorganic sulfate, with a mean of $13.7 \pm 5.6$ per cent.

\section{Studies with synthetic bilirubin sulfate}

Watson has described that bilirubin, when treated with sulfuric acid in the Liebermann-
Burchard reaction for cholesterol, is converted to a direct-reacting pigment (14). More recently he has indicated that a sulfate derivative of bilirubin is formed in the reaction (15). We have likewise observed that treatment of bilirubin with sulfuric acid, chlorosulfonic acid or the Liebermann-Burchard reagent results in a product which gives a "direct" Van den Bergh reaction.

When such reactions were carried out in the presence of radioactive sulfate and the products chromatographed, we noted results which suggested that more subtle alterations of the bilirubin molecule probably occurred during the course of these chemical interactions. Figure 5 is a composite of a typical experiment. It is seen in Chromatogram B (Figure 5), that three pigment derivatives are formed, the upper two having the characteristic red-blue appearance of an azopigment while the lower zone was green, and not diazotized. The center pigment zone, it will be noted, migrates with an $\mathrm{Rf}$ comparable to the main conjugated pigment zone of bile (Figure $5, \mathrm{~A})$. On the other hand, the autoradiograph of Chromatogram B (Figure 5,C) reveals that after the chemical reaction with sulfuric acid only the

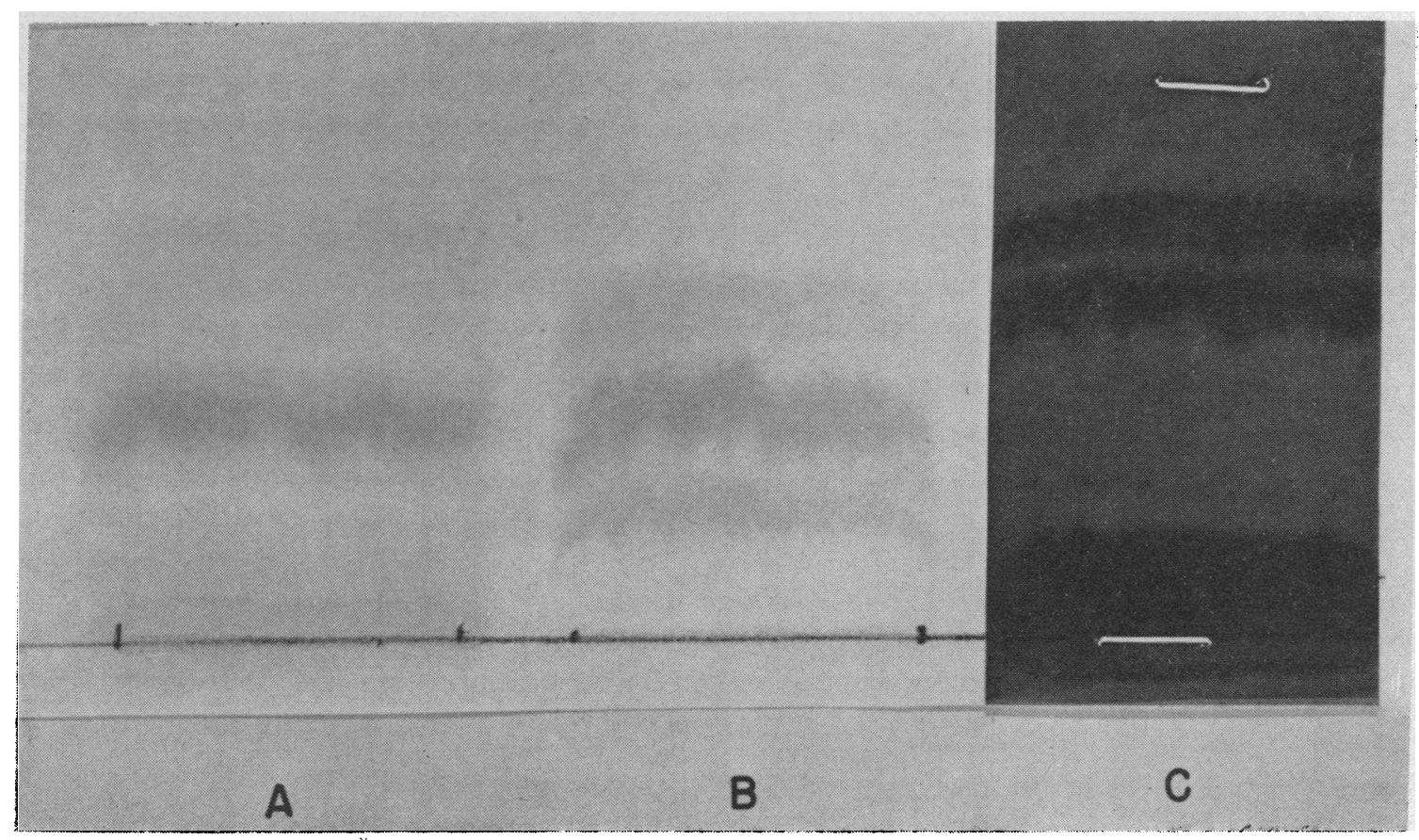

Fig. 5. Observations on Synthetic "Bilirubin Sulfate"

$A$ represents chromatography of normal bile azopigments in which the major band of pigment is conjugated. $B$ represents the products obtained after the diazotization of bilirubin which has previously been treated with Liebermann-Burchard reagent containing sulfuric acid and labeled sulfate. $C$ is the autoradiograph of $B$. 
upper of the three pigment derivatives of bilirubin contains radioactivity (i.e., sulfate). It is to be noted that the other two pigments are polar and water soluble and yet contain no radioactive sulfate. The other radioactive areas in the autoradiograph which do not correspond to any pigment zones are inorganic sulfate (at the origin) and polysulfate. It appears therefore that treatment of bilirubin with sulfuric acid, the Liebermann-Burchard reagent or chlorosulfonic acid results in changes of the pigment molecule which must extend beyond the simple addition of a sulfate radical.

Further evidence for structural alterations of the molecule occurring during the course of these reactions is the fact that when the products are subjected to acid hydrolysis in $6 \mathrm{~N} \mathrm{HCl}$, inorganic sulfate is liberated but pigment migrating as free azobilirubin is not detected. This is in distinct contrast to the acid hydrolysis of bile which results in the liberation of azobilirubin, readily identified by paper chromatography.

Finally, the absorption spectrum of the synthetic products (taken together) differs from that of the conjugated azopigments of human bile. The absorption maximum of the former in $0.5 \mathrm{~N}$ acetic acid is $550 \mathrm{~m} \mu$, while that of the latter is $532 \mathrm{~m} \mu$.

\section{DISCUSSION}

It is apparent from the above studies that although bilirubin glucuronide is the major conjugated bilirubin pigment, other polar and water soluble derivatives of bilirubin occur physiologically. That bilirubin sulfate is one of these conjugates is seen from the experiments with radioactive sulfate injection, analysis of the bile azopigments after exposure to $\beta$-glucuronidase and alkali, as well as chemical analysis. On a theoretical basis one would expect a sulfate derivative to be present in an alkali stable ether linkage at one of the hydroxyl groups of bilirubin. This is supported by the studies with hydroxylamine and diazomethane indicating that the carboxyl group is free. It is seen from the analyses in Table I that there must be still another fraction in human bile, amounting to 9 or 10 per cent, which contains neither glucuronide nor sulfate but is polar and alkali labile. Considering other known hepatic conjugation mechanisms (16) it is possible that these conjugates may be methyl or glycine derivatives of bilirubin linked at the carboxyl group. It is certainly evident that the main polar and conjugated azopigment zone as observed in the three paper chromatographic systems is not homogeneous or chemically pure.

The analyses of human $T$-tube bile for nong'ucuronide and sulfate derivatives do not permit a conclusion as to the existence of a monosulfate or a disulfate derivative of bilirubin. It is possible that bilirubin conjugates containing both glucuronic acid and sulfate occur, as in the case of morphine (17). It is furthermore conceivable that in the presence of liver disease, variations in the percentage of excreted glucuronide or sulfate derivatives may take place. In vitro observations in our laboratory indicate, for example, that the total glucuronide conjugating capacity of the mammalian liver declines readily with experimental liver damage (18).

Watson has reported that he was not able to detect any inorganic sulfate upon acid hydrolysis of the conjugated azopigment of bile after elution from paper chromatograms (15). However, since the method employed was a gravimetric one, it is very likely that small quantities of hydrolyzable sulfate escaped detection. We found in working with micromole quantities of pigment it was necessary to use the sensitive benzidine method of Dodgson and Spencer (9) to permit the detection and analysis of the inorganic sulfate liberated. Watson also expressed the view (15) that a naturally occurring bilirubin sulfate seemed unlikely since the Rf of synthetic "bilirubin sulfate" was different from the major conjugated azopigment zone on paper chromatography. For the reasons outlined above, we believe that treatment of bilirubin with sulfuric acid, as in the Liebermann-Burchard reaction, results in subtle changes of the pigment molecule beyond the introduction of a sulfate radical. In fact, as observed in Figure 5 , only one of the polar derivatives formed in this way contains sulfate. These observations, plus the fact that free azobilirubin is not liberated upon acid hydrolysis, suggest that the disparity in the $\mathrm{Rf}$ values of the natural azopigments and the synthetic product cannot be used to exclude the physiologic occurrence of bilirubin sulfate.

Additional evidence for the existence of a bilirubin sulfate conjugate is the fact that we have 
recently obtained evidence for the enzymatic synthesis of such a conjugate (19). This reaction has been observed in an ammonium sulfate fraction of rat liver. As was to be expected from the data of others on enzymatic sulfate conjugation (20), this system requires adenosine triphosphate. The "active sulfate" (adenosine- 3 ' phosphate-5' phosphosulfate) described by Robbins and Lipmann (21) is probably an intermediate in this synthesis.

\section{SUM MARY}

1. In addition to bilirubin glucuronide, nonglucuronide conjugates of bilirubin that are polar and water soluble occur physiologically. One of these conjugates, bilirubin sulfate, can readily be identified in the bile of rats, cats or man after the injection of radioactive sulfate. In contrast to bilirubin glucuronide, where the glucuronide is attached at the carboxyl groups, chemical studies suggest that the sulfate is linked at the hydroxyl groups of the pigment.

2. Additional evidence for the occurrence of nonglucuronide conjugates of bilirubin is provided by the presence of a conjugated azobilirubin fraction which resists $\beta$-glucuronidase hydrolysis and contains no glucuronic acid. A part of this fraction is stable to alkali.

3. Analyses of the bilirubin azopigments in 11 human $\mathrm{T}$-tube bile samples revealed a mean $\beta$ glucuronidase resistant fraction of $23.7 \pm 6.4$ per cent, a mean bilirubin sulfate content of $13.7 \pm$ 5.6 per cent and an alkali stable residue with a mean of $15.0 \pm 6.2$ per cent. These data suggest that there is yet another conjugated azobilirubin fraction amounting to 9 or 10 per cent, which is alkali labile and contains neither glucuronic acid nor sulfate.

4. Organic reactions can be used to form sulfate derivatives of bilirubin but they have the limitation of also producing other structural alterations in the bilirubin molecule.

\section{REFERENCES}

1. Isselbacher, K. J., and McCarthy, E. A. Identification of a sulfate conjugate of bilirubin in bile. Biochim. Biophys. Acta 1958, 29, 658.

2. Billing, B. H., and Lathe, G. H. The excretion of bilirubin as an ester glucuronide, giving the direct Van den Bergh reaction. Biochem. J. 1956, 63, 6 .
3. Billing, B. H., Cole, P. G., and Lathe, G. H. The excretion of bilirubin as a diglucuronide giving the direct Van den Bergh reaction. Biochem. J. 1957, 65, 774.

4. Schmid, R. Direct-reacting bilirubin, bilirubin glucuronide, in serum, bile and urine. Science 1956, 124, 76.

5. Talafant, E. On the nature of direct and indirect bilirubin. V. The presence of glucuronic acid in the direct bile pigment. Chem. Listy 1956, 50, 817.

6. Schachter, D. Nature of the glucuronide in directreacting bilirubin. Science 1957, 126, 507.

7. Schmid, R. The identification of "direct-reacting" bilirubin as bilirubin glucuronide. J. biol. Chem. 1957, 229, 881.

8. deBoer, T. J., and Backer, H. J. A new method for the preparation of diazomethane. Rec. Trav. chim. Pays-Bas 1954, 73, 229.

9. Dodgson, K. S., and Spencer, B. Studies on sulphatases. 5. The determination of inorganic sulphate in the study of sulphatases. Biochem. J. 1953, 55, 436.

10. Abell, L. L., Levy, B. B., Brodie, B. B., and Kendall, F. E. A simplified method for the estimation of total cholesterol in serum and demonstration of its specificity. J. biol. Chem. 1952, 195, 357.

11. Burkhardt, G. N., and Lapworth, A. Arylsulphuric acids. J. chem. Soc. 1926, 684.

12. Fishman, W. H., and Green, S. Microanalysis of glucuronide glucuronic acid as applied to $\beta$-glucuronidase and glucuronic acid studies. J. biol. Chem. 1955, 215, 527.

13. Dodgson, K. S., and Spencer, B. Assay of sulfatases in Methods of Biochemical Analysis, D. Glick, Ed. New York, Interscience Publishers, Inc., 1957, vol. 4, p. 211.

14. Watson, C. J. The importance of fractional serum bilirubin determinations in clinical medicine. Ann. intern. Med. 1956, 45, 351.

15. Watson, C. J. Color reaction of bilirubin with sulfuric acid: A direct diazo-reacting bilirubin sulfate. Science 1958, 128, 142.

16. Williams, R. T. Detoxication Mechanisms; The Metabolism of Drugs and Allied Organic Compounds. New York, John Wiley and Sons, 1947.

17. Woods, L. A. Distribution and fate of morphine in non-tolerant and tolerant dogs and rats. J. Pharmacol. exper. Therap. 1954, 112, 158.

18. Isselbacher, K. J. Unpublished observations.

19. Isselbacher, K. J., and McCarthy, E. A. Identification and analysis of nonglucuronide conjugates of bilirubin in human bile. Clin. Res. In press.

20. DeMeio, R. H., Wizerkaniuk, M., and Schreibman, I. Enzymatic system synthesizing sulfuric acid esters of phenols. J. biol. Chem. 1955, 213, 439.

21. Robbins, P. W., and Lipmann, F. Identification of enzymatically active sulfate as adenosine-3'-phosphate-5'phosphosulfate. J. Amer. chem. Soc. 1956, 78, 2652. 